\title{
Center of pressure-based postural sway differences on parallel and single leg stance in Olympic deaf basketball and volleyball players
}

\author{
Yücel Makaracı*, Recep Soslu, Ömer Özer, Abdullah Uysal \\ Faculty of Sports Sciences, Karamanoğlu Mehmetbey University, Karaman, Turkey
}

In sports such as basketball and volleyball, loss of balance due to the inability to maintain body stability and lack of postural control adversely affect athletic performance. Deaf athletes appear to struggle with balance and postural stability problems. The purpose of this study was to examine postural sway values in parallel and single leg stance of Olympic deaf basketball and volleyball players and reveal differences between the branches. Twenty-three male athletes from the Turkish national deaf basketball $(n=11)$ and volleyball $(n=12)$ teams participated in the study. After anthropometric measurements, the subjects completed postural sway (PS) tests in parallel/single leg stances with open eyes and closed eyes on a force plate. PS parameters (sway path, velocity, and area) obtained from the device software were used for the statistical analysis. The Mann-Whitney U-test was used to compare differences in PS parameters between basketball and volleyball players, and the alpha value was accepted as 0.05 . Volleyball players had significantly better results in parallel stance and dominant leg PS values than basketball players $(P<0.05)$. There was no significant difference between the groups in nondominant leg PS values $(P>0.05)$. We think that proprioceptive and vestibular system enhancing training practices to be performed with stability exercises will be beneficial in terms of both promoting functional stability and interlimb coordination. Trainers and strength coaches should be aware of differences in the postural control mechanism of deaf athletes.

Keywords: Balance, Basketball, Deaf, Body sway, Volleyball

\section{INTRODUCTION}

Hearing loss, which is defined as a problem in the ossicles of the middle ear in the transmission of sound, is stated as one of the most common types of disability, and there are approximately 360 million deaf individuals in the world, according to the World Health Organization (WHO) (Vita and Bruno, 2021; Zakeri and Taghian, 2020). Although hearing loss or impairment is mostly a communication-related problem, it can also be associated with other health factors such as balance defects or damage of sensory integration and motor development (Carpenter and Campos, 2020). Moreover, people with hearing impairment have difficulty performing daily balance-based activities (Gheysen et al., 2008). Sports are considered an important means of preventing medical problems of deaf individuals resulting from hearing loss and possible communication problems (Kurková et al., 2011). In recent years, it has been observed that participation in sports branches designed for individuals with disabilities and specially organized competitions has increased (McLoughlin et al., 2017). Although disabled individuals have disadvantages in terms of sports, the modification of sports branches according to the type of disability minimizes the difficulties caused by the disability and provides the requirements of the branch at an optimum level (Akınoğlu and Kocahan, 2019a). Among disabled athletes, those who are deaf participate in sports competitions without any restrictions because they do not have any physical deficiencies (Kurková et al., 2011).

It has been reported that the proper functioning of hearing organs significantly depends on postural stability (Walicka-Cupryś
*Corresponding author: Yücel Makaracı (iD https://orcid.org/0000-0002-6891-9916 Faculty of Sport Sciences, Karamanoğlu Mehmetbey University, Karaman 70200, Turkey

Email: yucelmkrc@gmail.com

Received: September 23, 2021 / Accepted: October 22, 2021
This is an Open Access article distributed under the terms of the Creative Commons Attribution Non-Commercial License (https://creativecommons.org/licenses/by-nc/4.0/) which permits unrestricted non-commercial use, distribution, and reproduction in any medium, provided the original work is properly cited. 
et al., 2014). In this context, body stabilization is a concept that comes to the fore when examining the athletic performance levels of deaf athletes participating in physical activities or sports competitions. For the body to stay upright and maintain this position, the sensory system must function faultlessly (Asadi et al., 2015; Hansson et al., 2010). Balance and postural stability are the basis of voluntary motor activities. Therefore, together with the integration of sensory outputs such as visual, vestibular, and proprioceptive ones, the harmony of motor and visual neurophysiological mechanisms is a requirement for postural stability (de Sousa et al., 2012). Considering the effect of the vestibular system on postural control, it is clear that possible vestibular problems will affect postural control adversely. A lack of postural control or swaying to a certain side (mediolateral, anteroposterior, etc.) limits basic sporting skills (Burke-Doe et al., 2008). Accordingly, Akınoğlu and Kocahan (2019b) stated that stabilization and balance training positively affected muscle strength and balance in deaf karate athletes. Zarei and Norasteh (2021) reported that an 8-week stability training program improved trunk muscle endurance in deaf individuals. Zarei et al. (2020) also indicated that 8-week pilates training significantly improved balance in female deaf students. As a result, it is evident that the concept of postural control should be the focus when the performance outputs of deaf athletes are evaluated.

Performance of the balance/postural control system is commonly evaluated in the laboratory by quantifying sway during a quiet upright stance. The most commonly used measures of postural sway are varied parameters derived from temporal patterns of the center of pressure (CoP) (Lin et al., 2008). Traditional assessment of CoP-based postural sway measures involve the measurements during different stance types and durations. $\mathrm{CoP}$ data across longer trials increases the reliability of the measurements (Kozinc et al., 2021). Sway path, sway area, sway velocity (anterior-posterior; medial-lateral), and ellipse area are some of the common CoP-based measures and especially have been related to postural stability and the risk of falls (Greene et al., 2012; Roman-Liu, 2018; Vsetecková and Drey, 2013). In athletes, postural control contributes to developing specific postural strategies required by a specific sport and acquiring new abilities in balance control according to the discipline of the training practiced on athletes. Studies investigating postural control in basketball and volleyball players are gaining importance in this respect. Loss of balance that may arise due to the inability to maintain body stability in sports such as basketball and volleyball, which heavily involve side steps, changing direction, stopping/acceleration, and sudden (vertical/horizontal) jumps, adversely affects athletic performance (motoric skills) (Agos- tini et al., 2013; Zemková and Hamar, 2014) because athletes perform numerous jumping/landing and sprint-based movements during competitions or training (Taylor et al., 2017). Therefore, balance is considered a natural requirement in exhibiting motoric movements (Hrysomallis, 2011).

The present study will contribute to the literature, which contains a limited number of studies, since it focuses on reflecting a concept characterized by the vestibular system, such as postural control, in Olympic deaf athletes. The purpose of this study was to examine postural sway values in parallel and single leg stance of Olympic deaf basketball and volleyball players and reveal differences between the branches.

\section{MATERIALS AND METHODS}

\section{Study design}

A purposive sampling method was used to investigate the postural sway values of the national deaf men's team basketball and volleyball players. All subjects completed postural sway tests under different conditions: (a) parallel stance open eyes (OE), (b) parallel stance closed eyes (CE), (c) single leg stance $\mathrm{OE}$, and (d) single leg stance $\mathrm{CE}$ on a force plate device detailed below. The athletes performed a 10-min general warm-up phase before starting the test. The subjects were tested twice consecutively in each stance, and the average of the two test administrations was used to calculate the test results. The subjects did not perform any exercise and training programs during the study period. To reduce the interference of uncontrolled variables, all subjects were instructed to maintain their usual way of life and routine diet program intake before and during the study. During the testing, only water was allowed as a drink.

The study was conducted before the 2021 European Deaf Basketball and World Volleyball Championship camping period of the athletes. The measurements were taken at the same time of day (i.e., mid-day) by the same researcher to control the effects of the circadian rhythm. A sign language translator in the interaction with hearing-impaired players was present throughout the study to explain the test procedures. A separate familiarization session before the testing day was not deemed necessary since this is not required with participants of this level (Makarac1 et al., 2021; Psycharakis et al., 2019).

\section{Participants}

Twenty-three male athletes from the Turkish national deaf basketball ( $n=11$; age, $25.18 \pm 4.57$ years; all with the dominant right 
leg) and volleyball ( $n=12$; age, $24.42 \pm 4.42$ years; all with the dominant right leg) teams participated in the study. The selection criteria of the athletes were as follows: being older than 18 years old, having a medically diagnosed hearing impairment condition (a hearing level in both ears $>55 \mathrm{~dB}$ without cochlear implantation), ability to understand basic instructions, being a member of the 2021 national deaf men's basketball and/or volleyball team, being a basketball and/or volleyball player for at least 3 years, and volunteering to participate in this study. The elimination criteria included the following: suffering from cervical and/or lumbar disc herniation, having any kind of orthopedic problem, having a recent acute injury causing cognitive, physical, or visual impairments, and having any neurological, orthopedic, or cardiovascular diseases.

All subjects signed informed consent forms. Ethical approval (Document No: 26794, 2021) was obtained from the Clinical Research Ethics Committee of Karamanoğlu Mehmetbey University, in accordance with the Declaration of Helsinki.

\section{Anthropometric variables}

The athletes' body weight was measured by a force plate (automatically before testing), and their height was measured by a stadiometer (SECA-Mod. 220, Seca GmbH \& Co. KG., Hamburg, Germany). The formula used to calculate the body mass index (BMI) is weight in kilograms $(\mathrm{kg})$ divided by height in meters $(\mathrm{m})$ squared (Makaracı et al., 2021).

\section{Postural sway assessment}

A force plate (Kistler, type $5691 \mathrm{~A}, 40 \mathrm{~cm} \times 60 \mathrm{~cm}$; Winterthur,
Switzerland) was used to assess postural sway by determining $\mathrm{CoP}$ for each subject and calculating the difference in range over time. The forces are measured in three axes, $x, y$, and $z$.

Firstly, parallel stance (feet apart), then single leg stance (dominant and nondominant legs) postural sway values of the subjects were measured. In a parallel stance, the subject is standing in the center of the force plate with the feet placed close together and shifted longitudinally against each other. In a single leg stance, the subject is standing on one leg in the center of the force plate. The foot is oriented in the anterioposterior direction (along the Y-axis of the force plate), with the toes pointing anteriorly $(+\mathrm{Y})$. Throughout the measurement, the subject sustains his normal upright stance position and places his hands on the hips. All measurements were conducted in $\mathrm{OE}$ and $\mathrm{CE}$ conditions. During the $\mathrm{OE}$ standing conditions, the participants were instructed to focus on an " $x$ " placed at eye level on the wall in front of them. Since shorter time intervals during the body sway measurements are associated with lower reliability (Kozinc et al., 2021), we chose to analyze body sway by comparing 30-sec intervals during the parallel stance (Sturnieks et al., 2011). A 10-sec duration was selected during single leg stance tests due to the difficulty of testing (Goetschius et al., 2018). The subjects wore walking shoes and were asked to stand still and keep their arms at their sides.

The force plate collected ground reaction forces at a $120-\mathrm{Hz}$ sampling frequency. The $\mathrm{CoP}$ measures included $\mathrm{CoP}$ path length, mean velocity and area. The postural sway parameters obtained from the Kistler Measurement, Analysis and Reporting Software (MARS, v4.0.2.99) were used for statistical analysis (Table 1). Di-

Table 1. Summary of the outcome postural sway measures, abbreviation, and descriptions

\begin{tabular}{|c|c|c|}
\hline Outcome measure & Abbreviation & Description \\
\hline Sway path-time (mm) & Sway Path-T & The common length of the trajectory of the CoP sway calculated as a sum of the point-to-point Euclidian distances \\
\hline Sway path-anterior-posterior (mm) & Sway Path-AP & The common length of the trajectory of the CoP sway only in the anterior-posterior direction. \\
\hline Sway path-Medial-Lateral (mm) & Sway Path-ML & The common length of the trajectory of the CoP sway only in the medial-lateral (i.e., left-right) direction. \\
\hline Sway velocity-time (mm/sec) & Sway V-T & $\begin{array}{l}\text { The common length of the trajectory of the CoP sway calculated as a sum of the point-to-point Euclidian distances } \\
\text { divided by the measurement time. }\end{array}$ \\
\hline $\begin{array}{l}\text { Sway velocity-anterior-posterior } \\
(\mathrm{mm} / \mathrm{sec})\end{array}$ & Sway V-AP & $\begin{array}{l}\text { The common length of the trajectory of the CoP sway only in the anterior-posterior direction divided by the } \\
\text { measurement time. }\end{array}$ \\
\hline $\begin{array}{l}\text { Sway velocity-medial-aateral } \\
\text { (mm/sec) }\end{array}$ & Sway V-ML & $\begin{array}{l}\text { The common length of the trajectory of the CoP sway only in the medial-lateral direction divided by the measurement } \\
\text { time. }\end{array}$ \\
\hline Sway area-total $\left(\mathrm{mm}^{2}\right)$ & Sway Area-T & $\begin{array}{l}\text { Area swayed by the CoP trajectory with respect to the central stance point (i.e., mean value of anterior-posterior and } \\
\text { medial-lateral components respectively). }\end{array}$ \\
\hline $\begin{array}{l}\text { Sway area-anterior-posterior } \\
\text { (mm/sec) }\end{array}$ & Sway Area-AP & $\begin{array}{l}\text { The time integral of the anterior-posterior component of the } \mathrm{CoP} \text { with respect to the mean value of anterior-posterior } \\
\text { component. }\end{array}$ \\
\hline $\begin{array}{l}\text { Sway area- medial-lateral } \\
\text { (mm/sec) }\end{array}$ & Sway Area-ML & $\begin{array}{l}\text { The time integral of the medial-lateral component of the } \mathrm{CoP} \text { with respect to the mean value of medial-lateral } \\
\text { component. }\end{array}$ \\
\hline Ellipse area of $\mathrm{CoP}\left(\mathrm{mm}^{2}\right)$ & EA-CoP & The area of the ellipse fitted over the CoP trajectory so that it contains $100 \%$ of all the data points. \\
\hline
\end{tabular}

CoP, center of pressure. 
agrams referring to a single study participant during each standing condition are shown in Fig. 1.

\section{Statistical analysis}

Before starting this study, a power analysis was performed to determine the number of athletes required, and a sample size of 10 athletes per group was estimated to have a power of 0.95 at $\alpha=$ 0.05 . The statistics of descriptive variables (age, height, weight, and $\mathrm{BMI}$ ) were reported using mean and standard deviation (mean $\pm \mathrm{SD}$ ). The normality of distribution was tested by the Kolmogorov-Smirnov test and skewness/kurtosis values. Since our data were not normally distributed, the Mann-Whitney $U$-test was conducted to compare differences in the mean values of postural sway parameters between basketball and volleyball players. IBM SPSS Statistics ver.
24.0 (IBM Co., Armonk, NY, USA) was used for statistical data analyses. For all analyses, the threshold for statistical significance was set at $P<0.05$. Effect sizes (ES) are reported based on Cohen recommendations: where $0.2-0.49$ is a small effect, $0.5-0.79$ is a moderate effect, and $\geq 0.8$ is a large effect (Nunes et al., 2021).

\section{RESULTS}

Baseline characteristics are presented in Table 2, and there are no significant differences between the groups (basketball and volleyball players) $(P>0.05)$. Table 2 presents the characteristics related to age, height, weight, and BMI of the subjects. The results show no significant differences between the age, height, weight, and BMI of the groups.

\section{Open Eyes}

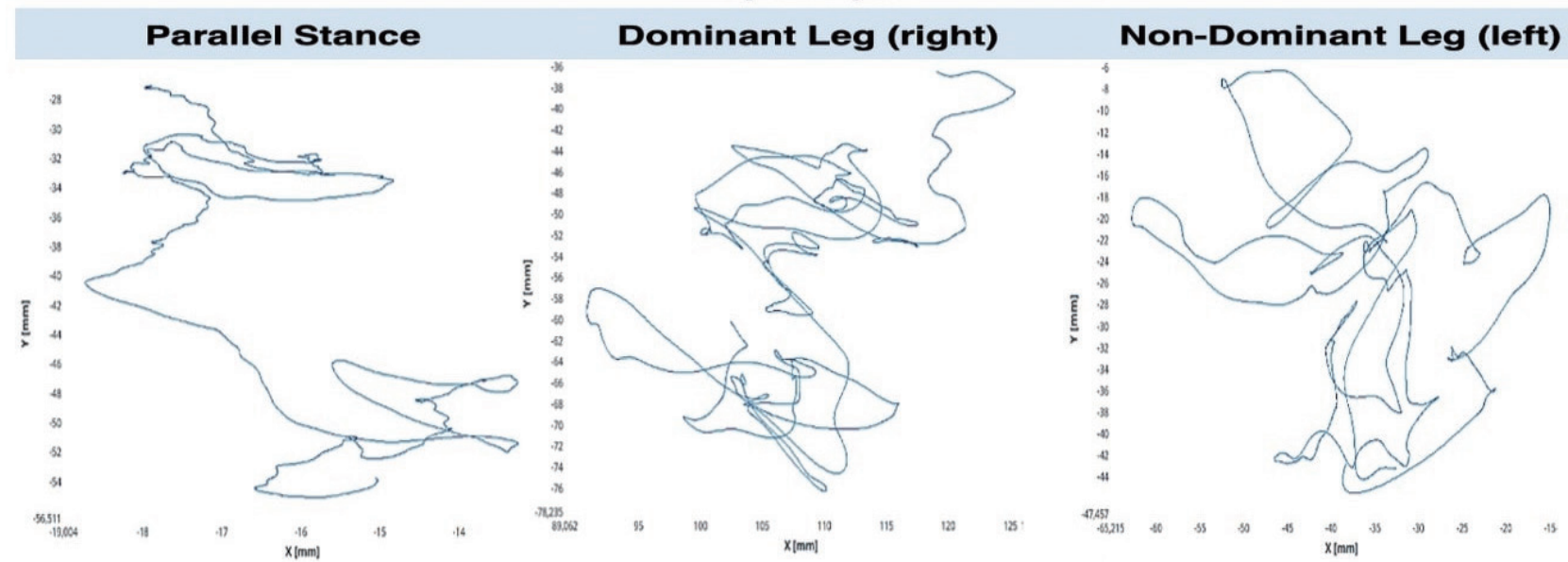

Closed Eyes

Parallel Stance

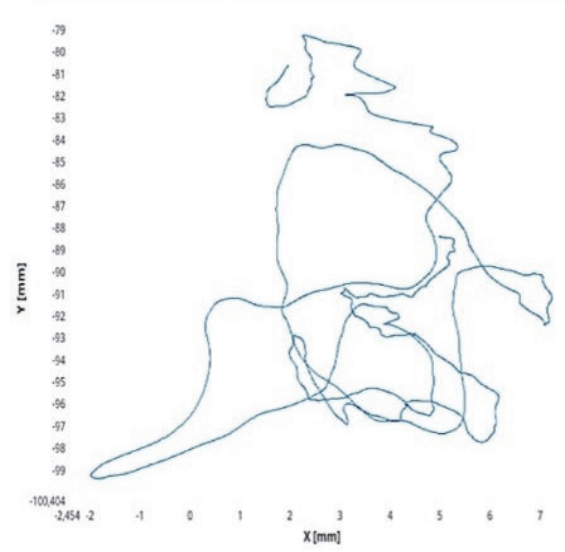

Dominant Leg (right)

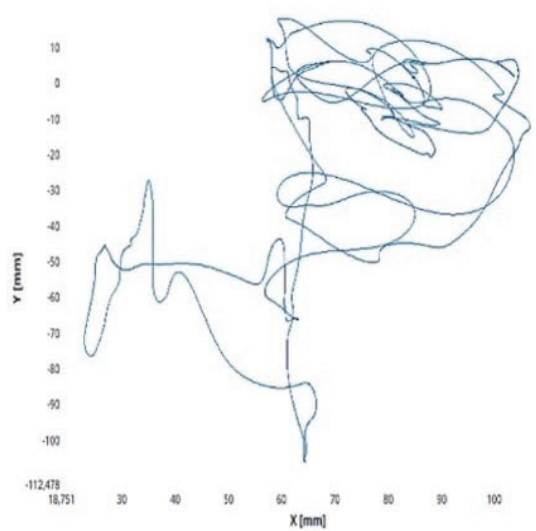

Non-Dominant Leg (left)

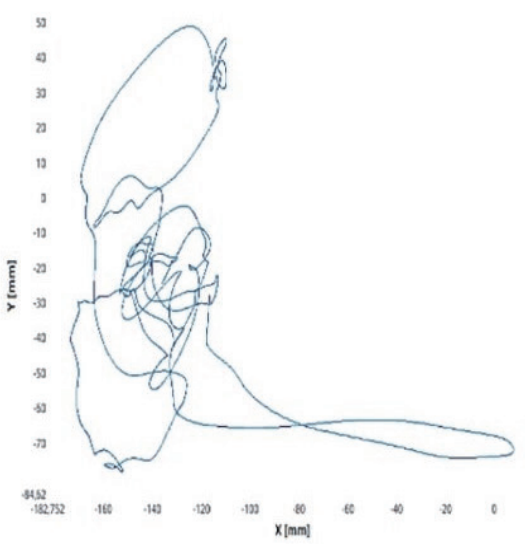

Fig. 1. Representative postural sway diagram from a single study participant during each standing conditions. The postural sway parameters obtained from the Kistler Measurement, Analysis and Reporting Software. 
$\mathrm{OE}$ and CE parallel stance postural sway parameters of the athletes and the comparison results between the groups are shown in Table 3. When the parallel stance measurements performed with $\mathrm{OE}$ in Table 3 were examined, a statistical difference was observed in the values of Sway Path-T, Sway Path-ML, Sway V-T, Sway

Table 2. Comparison of demographics variables of the groups

\begin{tabular}{llcrcc}
\hline Variable & Group & No. & Mean \pm SD & $P$-value & ES \\
\hline Age $(\mathrm{yr})$ & Basketball & 11 & $25.18 \pm 4.57$ & 0.407 & 0.17 \\
& Volleyball & 12 & $24.42 \pm 4.42$ & & \\
Height $(\mathrm{m})$ & Basketball & 11 & $1.84 \pm 0.10$ & 0.720 & 0.35 \\
& Volleyball & 12 & $1.87 \pm 0.07$ & & \\
Weight $(\mathrm{kg})$ & Basketball & 11 & $83.88 \pm 22.01$ & 0.291 & 0.20 \\
& Volleyball & 12 & $80.47 \pm 9.44$ & & \\
BMI $\left(\mathrm{kg} / \mathrm{m}^{2}\right)$ & Basketball & 11 & $24.55 \pm 4.36$ & 0.851 & 0.40 \\
& Volleyball & 12 & $23.08 \pm 2.65$ & & \\
Sports years (yr) & Basketball & 11 & $6.63 \pm 1.63$ & 0.322 & 0.43 \\
& Volleyball & 12 & $7.42 \pm 2.03$ & & \\
\hline
\end{tabular}

ES, effect sizes; BMI, body mass index.

Cohen $d$ effect size where $0.2-0.49$ is a small effect, $0.5-0.79$ is a moderate effect, and $\geq 0.8$ is a large effect.
V-AP, Sway V-ML, Sway Area-ML, and EA-CoP between the groups $(P \leq 0.05)$. The difference in the parameters of Sway Path-T, Sway Path-ML, Sway V-T, Sway V-AP, Sway V-ML, and EA-CoP was found to be a "large effect (ES=1.67, 1.03, 0.99, 1.10, 1.35, 1.23 , respectively)" and the difference in the Sway Area-ML parameter was found to be a "moderate effect (ES= 0.78$)$ " according to the "effect size (Cohen $d$ )" classification. In the difference between the groups, the arithmetic mean values of volleyball players are observed to be lower. This result indicates that volleyball players are in a better condition than basketball players in terms of parallel stance postural sway. In the postural sway measurements performed with $\mathrm{CE}$, no statistical difference was observed in the values between the groups $(P>0.05)$.

$\mathrm{OE}$ and $\mathrm{CE}$ dominant leg postural sway parameters of the athletes and the comparison results between the groups are shown in Table 4. When the dominant leg measurements performed with $\mathrm{CE}$ in Table 4 were examined, a statistical difference was observed in the values of Sway Path-T, Sway Path-AP, Sway V-T, and Sway $\mathrm{V}$-AP between the groups $(P \leq 0.05)$. The difference in the parameters of Sway Path-T, Sway Path-AP, and Sway V-AP was found to

Table 3. Parallel stance postural sway results of athletes

\begin{tabular}{|c|c|c|c|c|c|c|c|c|}
\hline \multirow{2}{*}{ Parameter } & \multirow{2}{*}{ Group } & \multirow{2}{*}{ No. } & \multicolumn{3}{|c|}{ Eyes opened } & \multicolumn{3}{|c|}{ Eyes closed } \\
\hline & & & Mean \pm SD & $P$-value & ES & Mean \pm SD & $P$-value & ES \\
\hline \multirow[t]{2}{*}{ Sway path-time (mm) } & Basketball & 11 & $162.94 \pm 58.27$ & $0.014^{*}$ & 1.67 & $171.41 \pm 84.75$ & 0.718 & 0.24 \\
\hline & Volleyball & 12 & $90.73 \pm 17.52$ & & & $208.41 \pm 200.15$ & & \\
\hline \multirow[t]{2}{*}{ Sway path-anterior-posterior (mm) } & Basketball & 11 & $101.44 \pm 47.99$ & 0.199 & 0.40 & $132.86 \pm 67.60$ & 0.907 & 0.07 \\
\hline & Volleyball & 12 & $81.57 \pm 50.28$ & & & $128.49 \pm 57.53$ & & \\
\hline \multirow[t]{2}{*}{ Sway path-medial-lateral (mm) } & Basketball & 11 & $66.64 \pm 27.15$ & $0.026^{*}$ & 1.03 & $80.09 \pm 43.65$ & 0.916 & 0.19 \\
\hline & Volleyball & 12 & $44.89 \pm 11.92$ & & & $72.91 \pm 30.40$ & & \\
\hline \multirow[t]{2}{*}{ Sway velocity-time (mm/sec) } & Basketball & 11 & $16.30 \pm 10.03$ & $0.020^{*}$ & 0.99 & $17.14 \pm 8.47$ & 0.509 & 0.36 \\
\hline & Volleyball & 12 & $9.32 \pm 2.10$ & & & $14.47 \pm 5.95$ & & \\
\hline \multirow[t]{2}{*}{ Sway velocity-anterior-posterior (mm/sec) } & Basketball & 11 & $10.14 \pm 4.80$ & $0.008^{* *}$ & 1.10 & $13.29 \pm 6.76$ & 0.907 & 0.07 \\
\hline & Volleyball & 12 & $6.40 \pm 1.14$ & & & $12.85 \pm 5.75$ & & \\
\hline \multirow[t]{2}{*}{ Sway velocity-medial-lateral (mm/sec) } & Basketball & 11 & $7.17 \pm 2.68$ & $0.005^{* *}$ & 1.35 & $8.15 \pm 4.34$ & 0.675 & 0.34 \\
\hline & Volleyball & 12 & $4.37 \pm 1.03$ & & & $6.91 \pm 2.70$ & & \\
\hline \multirow[t]{2}{*}{ Sway area-total $\left(\mathrm{mm}^{2}\right)$} & Basketball & 11 & $132.64 \pm 77.76$ & 0.410 & 0.44 & $174.99 \pm 107.11$ & 0.601 & 0.14 \\
\hline & Volleyball & 12 & $103.70 \pm 49.20$ & & & $189.76 \pm 104.65$ & & \\
\hline \multirow[t]{2}{*}{ Sway Area-Anterior-Posterior (mm/sec) } & Basketball & 11 & $53.04 \pm 23.23$ & 0.148 & 0.68 & $47.41 \pm 24.04$ & 0.607 & 0.11 \\
\hline & Volleyball & 12 & $39.19 \pm 16.78$ & & & $49.73 \pm 17.77$ & & \\
\hline \multirow[t]{2}{*}{ Sway area-medial-lateral (mm/sec) } & Basketball & 11 & $16.79 \pm 7.05$ & $0.038^{*}$ & 0.78 & $18.39 \pm 8.67$ & 0.214 & 0.64 \\
\hline & Volleyball & 12 & $11.22 \pm 6.68$ & & & $13.82 \pm 5.21$ & & \\
\hline \multirow[t]{2}{*}{ Ellipse area $\left(\mathrm{mm}^{2}\right)$} & Basketball & 11 & $39.55 \pm 25.59$ & $0.011^{*}$ & 1.23 & $40.51 \pm 27.27$ & 0.568 & 0.42 \\
\hline & Volleyball & 12 & $15.74 \pm 8.43$ & & & $30.61 \pm 18.80$ & & \\
\hline
\end{tabular}

ES, effect sizes.

Cohen $d$ effect size where $0.2-0.49$ is a small effect, $0.5-0.79$ is a moderate effect, and $\geq 0.8$ is a large effect.

${ }^{*} P<0.05$. ${ }^{*} P<0.01$. 
be a "large effect $(\mathrm{ES}=1.59,0.88,0.90$, respectively)," and the difference in the Sway V-T parameter was found to be a "moderate effect (ES=0.77)" according to the "effect size (Cohen $d)$ " classification. In the difference between the groups, the arithmetic mean values of volleyball players are observed to be lower. This result indicates that volleyball players are in a better condition than basketball players in terms of dominant leg postural sway. In the postural sway measurements performed with $\mathrm{OE}$, no statistical difference was observed in the values between the groups $(P>0.05)$.

Statistically significant dominant leg postural sway findings of the athletes are presented in Fig. 2. Fig. 2 shows that the Sway Path-T, Sway Path-AP, Sway V-T, and Sway V-AP parameters of the dominant leg were significantly lower in volleyball players than basketball players $(P=0.001, P=0.037, P=0.048$, and $P=$ 0.028 , respectively).

$\mathrm{OE}$ and $\mathrm{CE}$ nondominant leg postural sway parameters of the athletes and the comparison results between the groups are shown in Table 5. Upon reviewing Table 5, there was an inclination in favor of basketball players regarding the arithmetic means of postural sway in nondominant leg measurements performed with $\mathrm{OE}$

Table 4. Dominant leg (right) postural sway results of athletes

\begin{tabular}{|c|c|c|c|c|c|c|c|c|}
\hline \multirow{2}{*}{ Parameter } & \multirow{2}{*}{ Group } & \multirow{2}{*}{ No. } & \multicolumn{3}{|c|}{ Eyes opened } & \multicolumn{3}{|c|}{ Eyes closed } \\
\hline & & & Mean \pm SD & $P$-value & ES & Mean \pm SD & $P$-value & ES \\
\hline \multirow[t]{2}{*}{ Sway path-time (mm) } & Basketball & 11 & $565.95 \pm 167.87$ & 0.619 & 0.21 & $2,033.55 \pm 536.77$ & $0.001^{* * *}$ & 1.59 \\
\hline & Volleyball & 12 & $530.05 \pm 173.58$ & & & $1,337.23 \pm 302.34$ & & \\
\hline \multirow[t]{2}{*}{ Sway path-anterior-posterior (mm) } & Basketball & 11 & $340.94 \pm 81.35$ & 0.241 & 0.46 & $1,421.10 \pm 652.68$ & $0.037^{*}$ & 0.88 \\
\hline & Volleyball & 12 & $301.73 \pm 85.96$ & & & $956.08 \pm 366.47$ & & \\
\hline \multirow[t]{2}{*}{ Sway path-medial-lateral (mm) } & Basketball & 11 & $386.05 \pm 143.18$ & 0.973 & 0.06 & $1,072.16 \pm 224.98$ & 0.375 & 0.26 \\
\hline & Volleyball & 12 & $377.39 \pm 135.24$ & & & $998.44 \pm 371.28$ & & \\
\hline \multirow[t]{2}{*}{ Sway velocity-time (mm/sec) } & Basketball & 11 & $56.60 \pm 16.79$ & 0.568 & 0.23 & $203.36 \pm 53.69$ & $0.048^{*}$ & 0.77 \\
\hline & Volleyball & 12 & $52.57 \pm 17.45$ & & & $160.22 \pm 58.55$ & & \\
\hline \multirow[t]{2}{*}{ Sway velocity-anterior-posterior (mm/sec) } & Basketball & 11 & $34.10 \pm 8.14$ & 0.325 & 0.38 & $142.12 \pm 65.27$ & $0.028^{*}$ & 0.90 \\
\hline & Volleyball & 12 & $30.80 \pm 8.88$ & & & $93.70 \pm 40.26$ & & \\
\hline \multirow[t]{2}{*}{ Sway velocity-medial-lateral (mm/sec) } & Basketball & 11 & $38.61 \pm 14.32$ & 0.900 & 0.02 & $107.22 \pm 22.49$ & 0.800 & 0.13 \\
\hline & Volleyball & 12 & $38.96 \pm 14.52$ & & & $114.02 \pm 66.33$ & & \\
\hline \multirow[t]{2}{*}{ Sway area-total $\left(\mathrm{mm}^{2}\right)$} & Basketball & 11 & $2,339.06 \pm 1,400.66$ & 0.860 & 0.03 & $28,421.36 \pm 13,441.75$ & 0.210 & 0.53 \\
\hline & Volleyball & 12 & $2,291.42 \pm 1,104.53$ & & & $21,783.92 \pm 11,102.12$ & & \\
\hline \multirow[t]{2}{*}{ Sway Area-Anterior-Posterior (mm/sec) } & Basketball & 11 & $86.38 \pm 39.80$ & 0.907 & 0.03 & $229.10 \pm 80.82$ & 0.993 & 0.01 \\
\hline & Volleyball & 12 & $87.71 \pm 40.41$ & & & $228.23 \pm 81.69$ & & \\
\hline \multirow[t]{2}{*}{ Sway area-medial-lateral (mm/sec) } & Basketball & 11 & $71.08 \pm 24.03$ & 0.554 & 0.33 & $314.56 \pm 146.84$ & 0.660 & 0.01 \\
\hline & Volleyball & 12 & $64.42 \pm 15.33$ & & & $313.58 \pm 183.10$ & & \\
\hline \multirow[t]{2}{*}{ Ellipse area $\left(\mathrm{mm}^{2}\right)$} & Basketball & 11 & $275.44 \pm 149.64$ & 0.317 & 0.54 & $3,659.55 \pm 2,101.13$ & 0.471 & 0.24 \\
\hline & Volleyball & 12 & $209.31 \pm 84.30$ & & & $3,167.82 \pm 1,988.61$ & & \\
\hline
\end{tabular}

ES, effect sizes.

Cohen $d$ effect size where $0.2-0.49$ is a small effect, $0.5-0.79$ is a moderate effect, and $\geq 0.8$ is a large effect.

${ }^{*} P<0.05$. ${ }^{* *} P<0.001$.
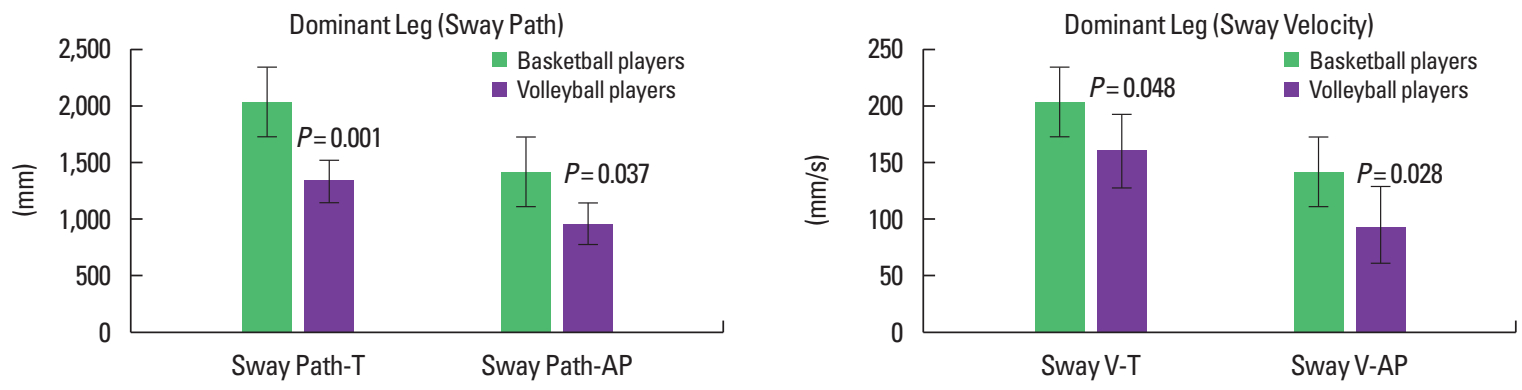

Fig. 2. Statistically significant dominant leg postural sway findings (parallel stance closed eyes) of the athletes. 
Table 5. Nondominant leg (left) postural sway results of athletes

\begin{tabular}{|c|c|c|c|c|c|c|c|c|}
\hline \multirow{2}{*}{ Parameter } & \multirow{2}{*}{ Group } & \multirow{2}{*}{ No. } & \multicolumn{3}{|c|}{ Eyes opened } & \multicolumn{3}{|c|}{ Eyes closed } \\
\hline & & & Mean $\pm S D$ & $P$-value & ES & Mean \pm SD & $P$-value & ES \\
\hline \multirow[t]{2}{*}{ Sway path-time (mm) } & Basketball & 11 & $693.16 \pm 246.55$ & 0.576 & 0.24 & $1,760.45 \pm 611.61$ & 0.404 & 0.38 \\
\hline & Volleyball & 12 & $756.91 \pm 278.56$ & & & $2,031.27 \pm 801.61$ & & \\
\hline \multirow[t]{2}{*}{ Sway path-anterior-posterior (mm) } & Basketball & 11 & $400.94 \pm 124.15$ & 0.726 & 0.09 & $1,189.42 \pm 466.49$ & 0.714 & 0.24 \\
\hline & Volleyball & 12 & $411.58 \pm 101.51$ & & & $1,347.48 \pm 814.12$ & & \\
\hline \multirow[t]{2}{*}{ Sway path-medial-lateral (mm) } & Basketball & 11 & $493.52 \pm 207.81$ & 0.697 & 0.16 & $1,003.12 \pm 362.01$ & 0.378 & 0.32 \\
\hline & Volleyball & 12 & $531.73 \pm 268.10$ & & & $1,115.13 \pm 332.93$ & & \\
\hline \multirow[t]{2}{*}{ Sway velocity-time (mm/sec) } & Basketball & 11 & $76.33 \pm 34.54$ & 0.869 & 0.09 & $1,76.05 \pm 61.16$ & 0.404 & 0.38 \\
\hline & Volleyball & 12 & $80.41 \pm 50.75$ & & & $203.14 \pm 80.17$ & & \\
\hline \multirow[t]{2}{*}{ Sway velocity-anterior-posterior (mm/sec) } & Basketball & 11 & $42.28 \pm 15.80$ & 0.713 & 0.28 & $118.95 \pm 46.65$ & 0.714 & 0.24 \\
\hline & Volleyball & 12 & $38.55 \pm 9.50$ & & & $134.77 \pm 81.42$ & & \\
\hline \multirow[t]{2}{*}{ Sway velocity-medial-lateral (mm/sec) } & Basketball & 11 & $52.40 \pm 24.73$ & 0.942 & 0.19 & $100.31 \pm 36.20$ & 0.378 & 0.32 \\
\hline & Volleyball & 12 & $48.43 \pm 15.89$ & & & $111.53 \pm 33.30$ & & \\
\hline \multirow[t]{2}{*}{ Sway area-total $\left(\mathrm{mm}^{2}\right)$} & Basketball & 11 & $3,793.55 \pm 2,125.78$ & 0.193 & 2.29 & $22,558.55 \pm 13,298.36$ & 0.217 & 0.50 \\
\hline & Volleyball & 12 & $9,899.75 \pm 3,111.73$ & & & $32,286.33 \pm 24,200.26$ & & \\
\hline \multirow[t]{2}{*}{ Sway Area-Anterior-Posterior (mm/sec) } & Basketball & 11 & $96.46 \pm 33.80$ & 0.178 & 0.67 & $229.29 \pm 97.41$ & 0.533 & 0.15 \\
\hline & Volleyball & 12 & $136.01 \pm 75.34$ & & & $243.71 \pm 89.17$ & & \\
\hline \multirow[t]{2}{*}{ Sway area-medial-lateral (mm/sec) } & Basketball & 11 & $106.02 \pm 58.51$ & 0.597 & 0.24 & $229.19 \pm 94.09$ & 0.058 & 1.02 \\
\hline & Volleyball & 12 & $124.46 \pm 91.79$ & & & $336.02 \pm 113.96$ & & \\
\hline \multirow[t]{2}{*}{ Ellipse area $\left(\mathrm{mm}^{2}\right)$} & Basketball & 11 & $378.10 \pm 255.82$ & 0.122 & 0.49 & $4,120.36 \pm 1,806.32$ & 0.784 & 0.23 \\
\hline & Volleyball & 12 & $484.85 \pm 175.01$ & & & $4,585.91 \pm 2,158.60$ & & \\
\hline
\end{tabular}

ES, effect sizes.

Cohen $d$ effect size where $0.2-0.49$ is a small effect, $0.5-0.79$ is a moderate effect, and $\geq 0.8$ is a large effect.

and CE. No statistical difference was found between the groups $(P>0.05)$.

\section{DISCUSSION}

Vestibular problems, which are common in deaf individuals, are known to affect postural control adversely (Stroh et al., 2021). In parallel, the concepts of balance and postural stability are considered among the most significant performance criteria in deaf athletes (Akınoğlu and Kocahan, 2018). The purpose of this study was to examine postural sway values in parallel and single leg stance of Olympic deaf basketball and volleyball players and reveal differences between the branches.

According to the study results, deaf volleyball players were observed to have better results in parallel stance and dominant leg postural sway values than basketball players $(P \leq 0.05)$ (Tables 3, 4). No difference was identified between branches in nondominant leg postural sway values (Table 5). When the parallel stance and single leg postural sway measurements performed with $\mathrm{OE}$ and $\mathrm{CE}$ are examined, it is observed that the mean $\mathrm{OE}$ values are better in both groups compared to the mean CE values. In parallel with this finding, in their study investigating the effect of hearing loss on physical performance parameters in elite athletes, Akınoğlu and Kocahan (2019b) reported a statistical difference (in favor of $\mathrm{OE}$ ) between balance performances with $\mathrm{OE}$ and $\mathrm{CE}$. This difference in the values of the $\mathrm{CE}$ protocol, which was realized in a much more difficult environment than the $\mathrm{OE}$ test protocol, seems normal for deaf individuals. In this context, balance and postural stability exercises are recommended, especially for athletes with hearing loss, to prevent performance losses. Akınoğlu and Kocahan (2019b) stated that stabilization and balance training positively affected muscle strength and balance in deaf karate athletes. Zakeri and Taghian (2020) indicated that 8-week resistance and core stability exercises improved the balance ability in deaf children. Furthermore, Zarei et al. (2020) reported that 8-week pilates training positively affected balance performance in female deaf students (age, 16.7 \pm 1.7 years). Moreover, proprioceptive intervention programs have been recommended in previous studies for deaf and normal-hearing individuals to maintain postural stability, vestibular function, and balance ability (Cyma-Wejchenig et al., 2020; Majlesi et al., 2014; Martínez-Amat et al., 2013; Wiesmeier et al., 2017). Thus, postural assessment, as well as benefiting from 
the training methods and practices mentioned above, should be taken into consideration while aiming to reduce the risks of performance loss and possible injury due to balance and postural stability problems of deaf athletes (Sabin et al., 2010). It is also well known that injuries of the lower extremities are common in team sports such as basketball and volleyball (Dallinga et al., 2012).

Considering differences in body stability between deaf and normal-hearing individuals, it is probable that there will be differences between sports branches in deaf athletes. This difference could be caused by learning achieved with respect to the branch after many years, leading to the development of joint proprioception. It is clear that keeping balance and postural stability at an optimum level will positively affect competition performance (Agostini et al., 2013) since side steps, changing direction, and sudden vertical/ horizontal jumps are extensively used in basketball and volleyball (Milić et al., 2013). According to the study results, it is an important finding for the literature that deaf volleyball players producehave statistically better results than basketball players in parallel stance and dominant leg postural sway values (Fig. 2). This difference is thought to especially result from the neuromuscular coordination, range of motion, and postural sway tendencies of the volleyball players who participated in the study, depending on the frequency of the actions specific to the sports branch, along with the variables such as a better morphological structure, body composition, and BMI. In the CE dominant leg comparison made in our study, it was revealed that sway path/velocity-based parameters differed in favor of volleyball players. It is assumed that the present finding is related to the effect of the dominant leg on sportive actions in volleyball. Moreover, it has been concluded that there may be an improvement in postural sway along with the improvement in dynamic balance over time since volleyball players are in more contact with the ground (ground reaction force) and constantly perform maneuvers such as spikes/blocks throughout the match. Considering the limited number of studies on the comparison of branches in deaf athletes, factors such as the use of the force plate device with a high validity and reliability in measurements and the sample group consisting of Olympic deaf athletes make the study findings valuable.

According to the results of the study, which examined the postural sway values of deaf basketball and volleyball players and presented the comparison between the branches, it was observed that volleyball players had better results in many postural sway parameters. Especially the difference in the dominant leg values in favor of deaf volleyball players is a significant finding. A possible reason for this may be that long-term practice in volleyball leads to bet- ter motor coordination performance and morphological structure. It is also believed that proprioceptive and vestibular system enhancing training practices to be performed with stability exercises (static and dynamic movements) will be beneficial in terms of both promoting functional stability and interlimb coordination. Special training programs (i.e., core stability, pilates) considering differences in the mediolateral, anteroposterior direction and sway velocities revealed in the present study could be useful for preventing possible sport-specific performance losses. Trainers and strength coaches should be aware of differences in the postural control mechanism. Thus, performing periodic postural analyses will be appropriate to determine and prevent the effect of postural abnormalities on body sway, especially in deaf athletes.

The limitations of our study included not having a female group. It is suggested that future researchers could determine if similar results exist in different types of sports. The findings of this study are specific to deaf basketball and volleyball players from our sample group, although all the subjects are at the Olympic level. More research is needed to identify whether our findings can be generalized to all deaf athletes from the same sports.

\section{CONFLICT OF INTEREST}

No potential conflict of interest relevant to this article was reported.

\section{ACKNOWLEDGMENTS}

The authors are very grateful to all the Turkish national deaf men basketball and volleyball players, coaching staff, and managers for their support during the study measurements. The authors received no financial support for this article.

\section{REFERENCES}

Agostini V, Chiaramello E, Canavese L, Bredariol C, Knaflitz M. Postural sway in volleyball players. Hum Mov Sci 2013;32:445-456.

Akınoğlu B, Kocahan T. Comparison of muscular strength and balance in athletes with visual impairment and hearing impairment. J Exerc Rehabil 2018;14:765-770.

Akınoğlu B, Kocahan T. The effect of deafness on the physical fitness parameters of elite athletes. J Exerc Rehabil 2019a;15:430-438.

Akınoğlu B, Kocahan T. Stabilization training versus equilibrium training in karate athletes with deafness. J Exerc Rehabil 2019b;15:576-583.

Asadi A, de Villarreal ES, Arazi H. The effects of plyometric type neuro- 
muscular training on postural control performance of male team basketball players. J Strength Cond Res 2015;29:1870-1875.

Burke-Doe A, Hudson A, Werth H, Riordan DG. Knowledge of osteoporosis risk factors and prevalence of risk factors for osteoporosis, falls and fracture in functionally independent older adults. J Geriatr Phys Ther 2008;31:11-17.

Carpenter MG, Campos JL. The effects of hearing loss on balance: a critical review. Ear Hear 2020;41:107-119.

Cyma-Wejchenig M, Tarnas J, Marciniak K, Stemplewski R. The influence of proprioceptive training with the use of virtual reality on postural stability of workers working at height. Sensors (Basel) 2020;20:3731.

Dallinga JM, Benjaminse A, Lemmink KAPM. Which screening tools can predict injury to the lower extremities in team sports? Sports Med 2012;42:791-815.

de Sousa AM, de França Barros J, de Sousa Neto BM. Postural control in children with typical development and children with profound hearing loss. Int J Gen Med 2012;5:433-439.

Gheysen F, Loots G, Van Waelvelde H. Motor development of deaf children with and without cochlear implants. J Deaf Stud Deaf Educ 2008; 13:215-224.

Goetschius J, Feger MA, Hertel J, Hart JM. Validating center-of-pressure balance measurements using the MatScan ${ }^{\circledR}$ pressure mat. J Sport Rehabil 2018;27:1-14.

Greene BR, McGrath D, Walsh L, Doheny EP, McKeown D, Garattini C, Cunningham C, Crosby L, Caulfield B, Kenny RA. Quantitative falls risk estimation through multi-sensor assessment of standing balance. Physiol Meas 2012;33:2049-2063.

Hansson EE, Beckman A, Håkansson A. Effect of vision, proprioception, and the position of the vestibular organ on postural sway. Acta Otolaryngol 2010;130:1358-1363.

Hrysomallis C. Balance ability and athletic performance. Sports Med 2011; 41:221-232.

Kozinc Ž, Trajković N, Šarabon N. Transient characteristics of body sway during single-leg stance in athletes with a history of ankle sprain. Gait Posture 2021;86:205-210.

Kurková P, Válková H, Scheetz N. Factors impacting participation of European elite deaf athletes in sport. J Sports Sci 2011;29:607-618.

Lin D, Seol H, Nussbaum MA, Madigan ML. Reliability of COP-based postural sway measures and age-related differences. Gait Posture 2008;28:337-342.

Majlesi M, Farahpour N, Azadian E, Amini M. The effect of interventional proprioceptive training on static balance and gait in deaf children. Res Dev Disabil 2014;35:3562-3567.

Makaracı Y, Özer Ö, Soslu R, Uysal A. Bilateral counter movement jump, squat and drop jump performances in deaf and normal-hearing vol- leyball players: a comparative study. J Exerc Rehabil 2021;17:339-347.

Martínez-Amat A, Hita-Contreras F, Lomas-Vega R, Caballero-Martínez I, Alvarez PJ, Martínez-López E. Effects of 12-week proprioception training program on postural stability, gait, and balance in older adults: a controlled clinical trial. J Strength Cond Res 2013;27:2180-2188.

McLoughlin G, Fecske CW, Castaneda Y, Gwin C, Graber K. Sport participation for elite athletes with physical disabilities: motivations, barriers, and facilitators. Adapt Phys Activ Q 2017;34:421-441.

Milić M, Grgantov Z, Katić R. Impact of biomotor dimensions on player quality in young female volleyball players. Coll Antropol 2013;37: 93-99.

Nunes AC, Cattuzzo MT, Faigenbaum AD, Mortatti AL. Effects of integrative neuromuscular training and detraining on countermovement jump performance in youth volleyball players. J Strength Cond Res 2021;35:2242-2247.

Psycharakis SG, Eagle SR, Moir GL, Rawcliffe A, Mckenzie C, Graham SM, Lamont HS, Connaboy C. Effects of additional load on the occurrence of bilateral deficit in counter-movement and squat jumps. Res $Q$ Exerc Sport 2019;90:461-469.

Roman-Liu D. Age-related changes in the range and velocity of postural sway. Arch Gerontol Geriatr 2018;77:68-80.

Sabin MJ, Ebersole KT, Martindale AR, Price JW, Broglio SP. Balance performance in male and female collegiate basketball athletes: influence of testing surface. J Strength Cond Res 2010;24:2073-2078.

Stroh AL, Rösler F, Röder B. The interaction of the visuo-spatial and the vestibular system depends on sensory experience in development. Neuropsychologia 2021;152:107736.

Sturnieks DL, Arnold R, Lord SR. Validity and reliability of the Swaymeter device for measuring postural sway. BMC Geriatr 2011;11:63.

Taylor JB, Wright AA, Dischiavi SL, Townsend MA, Marmon AR. Activity demands during multi-directional team sports: a systematic review. Sports Med 2017;47:2533-2551.

Vita L, Bruno D. The challenge of detecting cognitive impairment in hearing-impaired individuals. Eur J Neurol 2021;28:1795-1796.

Vsetecková JJ, Drey N. What is the role body sway deviation and body sway velocity play in postural stability in older adults? Acta Medica (Hradec Kralove) 2013;56:117-123.

Walicka-Cupryś K, Przygoda Ł, Czenczek E, Truszczyńska A, Drzał-Grabiec J, Zbigniew T, Tarnowski A. Balance assessment in hearing-impaired children. Res Dev Disabil 2014;35:2728-2734.

Wiesmeier IK, Dalin D, Wehrle A, Granacher U, Muehlbauer T, Dietterle J, Weiller C, Gollhofer A, Maurer C. Balance training enhances vestibular function and reduces overactive proprioceptive feedback in elderly. Front Aging Neurosci 2017;9:273.

Zakeri F, Taghian F. Comparing the effect of 8 weeks of total body resis- 
tance exercise and core stability training on selected common abnormalities and postural control in deaf adolescents. J Rehabil Sci Res 2020;7:87-95.

Zarei $\mathrm{H}$, Norasteh AA. Effects of core stability training program on trunk muscle endurance in deaf children: a preliminary study. J Bodyw Mov Ther 2021;28:6-12.
Zarei H, Norasteh AA, Rahmanpournashrudkoli A, Hajihoseini E. The effects of pilates training on static and dynamic balance of female deaf students: a randomized controlled trial. J Bodyw Mov Ther 2020;24: 63-69.

Zemková E, Hamar D. Physiological mechanisms of post-exercise balance impairment. Sports Med 2014;44:437-448. 